\title{
THE APPROACH OF MEDICAL MALPRACTICE PHENOMENON WITHIN THEORETICAL FRAMEWORK OF MEDICAL SOCIOLOGY
}

\author{
Radu-Mihai DUMITRESCU ${ }^{1}$ \\ DOI: 10.35782/JCPP.2019.4.04
}

\begin{abstract}
The medical malpractice represents a phenomenon which is more and more debated in the Romanian society; its connection with a series of other phenomena as those of the migration of physicians or decrease of physicians' credibility in the eyes of the public opinion can represent individual research subjects. The medical care has become a more complex process both by the social and economic developments (digitalization, technological development, demographic changes) and by the awareness at social level concerning the weak points and lacks the care systems. The higher costs of the medical care, the change of the physician - patient relationship, the ease access to online information, the unequal distribution of resources for health, the social inequity concerning the cares for bealth represent subjects from the area of medical sociology. The sociological approach of processes and phenomenon related to the medical treatments represent a useful systematic approach for their understanding or for the development of some adequate social policies. The objective of this paper is the identification of the ways in which the phenomenon of medical malpractice is represented in the theoretical field of sociology.
\end{abstract}

Key words: medical malpractice, sociological theories, sociology of medicine, content analysis

\section{Necessity of studying the concept of medical malpractice}

In 2000, the American Institute of Medicine has published a report which starts from a basis which cannot be doubted; the error is human and only starting from this point we can develop a safer medical system (Kohn, Corrigan 2000). The reconceptualization of medical care is necessary from the perspective of a system which makes possible the transformation of this cultural trend of guiltiness, which forced the individuals take defence measure and try to grant the liability for error - especially by the fact that no side events have been reported, in a trend of safety. The mentioned report brings information

${ }^{1}$ Phd Candidate in Sociology, Faculty of Sociology and Social Work, University of Bucharest, Senior Consultant in Anesthesia and Intensive Care, Medicover Hospital Bucharest, Email: dum_mihu@yahoo.com 
concerning the huge economic and human costs caused by the deviations from the patient's safety. The report To Err is Human: Building a Safer Health System has continued to have consequences in the discussions about the future of medical care both in the USA and abroad. The report has especially followed the side events. Two major studies performed in Colorado / Utah and in New York have found that the side events have occurred in 2,9 and, respectively, 3,7\% of the hospitalizations. In the first study, $6,6 \%$ of these events have led to a death, while in the study of New York the figure has been of $13.6 \%$. The extrapolation of these studies have led the authors to conclude that "at least 44.000 Americans die each year as consequence of a medical error" (Kohn, Corrigan, 2000). These numbers have not been accepted without representing a challenge for various involved parties. However, it has reached a large acceptance that hospitals, contrary to some primary perceptions, are extremely risky places.

The tests performed by this report are not immediately relevant for the health policies; it is necessary a "translation" of this information. An important phenomenon is the one of looping between the research performed by social sciences and the immediate concerns of policies performed in the field of health (Jensen, 2008).

\section{Introduction}

The sociological theories guide us rarely concerning the interventions of public health at community level or at the health system level as assembly. The reasons for which these are not clear contain difficulties in finding, understanding or operating theories. Starting from the fundamental methodological idea according to which it is essential to understand the theoretical framework to be able to propose a practical one, we have performed a study to explore the sociological theories in a certain public health field: medical malpractice, generally, as well as, if there are, references on a wider perspective, institutional, of the system one.

The search for a theory using electronic methods is problematic because many of them are published in books which are rarely well indexed in computerized databases. There are studies which have acknowledged that the sociological models and theories have been lost within some electronic searches, mostly if these have been developed more than 25 years (Kelly et al., 2010). The sociological theory could also be embedded in an empirical paper, being more difficult to be identified. Some theories are written in a denser and complicated way, making them difficult to be understood. There are also some opinions that the theories are not easy to operate; for example, Rogers perceives the sociology of medicine as one which generates complex explanations, but unable to be reduced in accurate, isolated elements (Rogers, 1968). This issue indicates, probably, the necessity of choosing a "middle range" theory and less some grand/general ones or, again, it could mean, simply, that the sociologists must present and explain clearly the proposed theories (Merton, 2007).

We consider these theories as important concerning their potential to inform, to modulate interactions between physician and patient and to orientate the interventions in the field of public health. The objectives of this article have been the identification of some sociological theories in a certain field of interest, in this case the medical malpractice. The purpose is not to perform a comprehensive search of all relevant 
sociological theories but, simply, to test the easiness with which the sociological theories can be accessed in a certain field and can be taken into consideration by their potential of practical use.

\section{The search strategies for sociological theories concerning malpractice}

We have assumed that the performance of a search on the terminology of medical malpractice could tend more towards a medical literature than towards a sociological literature, as we have initiated a manual search beginning with a search engine of an online library (Wiley Online Library) (recognizing that this objective drew my attention towards an extended view in the field of health, separated on certain medical subspecialties and towards areas of the world). Because the electronic searches are considered inaccurate for the identification of theoretical literature (Kelly et al., 2010) and because we have anticipated that the theories could be enclosed in a variety of methods and could use an unexpected terminology, we have performed a manual search. Since this has been an exploratory study, we have limited to the first 200 results offered by the library mentioned above; the search has been done using the key word "medical malpractice". Upon the interrogation of the database of 65 magazines have been identified in which between 1 and 27 articles which have had in their title or in their corpus the searched key word has been discovered. Subsequently, the search has headed towards the -sociological journals motivated that it would be mostly probable to find sociological theories in these magazines than in the general medical journals or in ones dedicated to a certain sub-specialty. By the analysis of articles only in one journal we have lost, without doubt, some relevant publications; however, my purpose has not been of performing an exhaustive search of all the relevant theories, but the orientation in a theoretical field relevant for a subsequent search.

Finally, 27 articles published in the magazine Sociology of Health and Illness have been analysed from content point of view of. We have performed an encoding of the content of these articles, and the identified themes have been reunited in the subchapter Content analysis.

The approach taken into consideration for the identification of sociological theories or perspectives in which light it is analysed the phenomenon of medical malpractice has had as starting point a study published in the magazine Sociology of Health and Illness (Seale, 2008) ${ }^{1}$; it has emphasized the tendencies of sub-specialty identified as medical sociology. One of the exposed starting points is the translation from a sociology in medicine to a sociology of medicine by adopting a more analytical and more critical methodology (Straus, 1957).

Another acknowledged matter and which we have considered important is the one referring to the approach method of various subjects in the specialty magazines; the tendency of authors has been towards an approach depending on the particularities of

${ }^{1}$ Mapping the field of medical sociology: a comparative analysis of journals, Sociology of Health \& Illness, 30: 677-695 
health systems from their origin countries contrasting with more extended, compared perspectives, observed at other disciplines from social sciences. The research mentioned above reveals the fact that the magazine Sociology of Health and Illness is an exception from this point of view, publishing articles with a wider vision (Seale, 2008). From the point of view of approaches based on sociological theories, the authors consider that the British researchers from the field of medical sociology are somehow "a-theoreticians" in comparison with those who publish in general sociology journals. In the magazines of the USA, the researchers from the medical sub-field seem, somehow, "apolitical" in comparison with those who publish in the magazines with general sociological approach. The latter have an approach which tends towards the quantitative researches (Seale, 2008).

Another important difference has been offered by Turner in 1995; he declares that there are three analysis levels. At the level of individual, it is emphasized the perception and experience concerning the health condition or disease. The second level is a social one which concerns the social constructions of various categories of diseases, as well as the causality with various social structural factors. The widest level of approach is a "societal" one which embeds the analysis of health systems at national and global level; this perspective is one which has as basis the political economy (Turner, 1995).

\section{Content analysis}

The articles from the journals dedicated to medical sociology bring definitions of malpractice similar with the legal approach which is maintained nowadays. To be constituted as case of malpractice it is necessary to meet various conditions: a plaintiff must prove that there has been the negligence, this negligence has lead or contributed to damages or injuries (generally damages) which can be objectified (Roger \& Joanne, 1985). Another approach which seems to remain current is the one in which the negligence or malpractice involve the failure to respect by the physician of the professional standards.

In theory, it is considered that the possibility that a patient address to the court, can be the result of two situations: (1) if there has been or not a damage by negligence and (2) if the patient (or the patient's lawyer) is aware of the negligence (in which situation, if decides and if it has resources); if one of these is met, the patient can choose to open a trial or another legal or administrative action. There have been comments as "the claims and complaints cannot offer the real image of the efficiency of medical practice; these are more a measure of the care degree as it is evaluated by the patient" (. Murray, 1984). These approaches have led to the opinions which state that the negligence is irrelevant in the case of malpractice. However, there is the suggestion that, the physician - patient relationships is used to adjust the patient's opinions, even when the physician feels that a complaint can become a solution to the problems caused by the typical positioning: the physician is positioned actively in the relationship while the patient adopts a passive role; it is very probably that the current realities have evolved a lot in this regard. The patient owns a certain control degree in this "alliance". The building of this type of relationship can meet difficulties from organizational point of view (even systematic), even if the will of the two parties is a real one. 
Since 1963, the American Medical Association (AMA) has recognized that the physician must "have the necessary skills to exercise the occupation which is similar to that exercised by other physicians from the same locality"; the physician must "continue to be a professional in the care for a patient as long as necessary" and "to perform any action for diagnostic or procedure for the improvement of patient's condition only with the expressed or implicitly consent" (Committee Report AMA 1963). The phenomenon related to malpractice in medicine reached visible proportions in the USA in the middle of 1970s. The subsequent analysis has shown that it has been promoted by the disputes related to the huge increases of insurance price for physicians, by the withdrawal from the exercise of occupation of many physicians and by a series of "physicians' strikes". In some American states, there have been hospitals forced to stop the activity or reduce the volume of services which they have provided (Somers, 1977). The action upon the functioning of the health system has obliged the legislative system to intervene fast and implement a legislative framework, which consolidates the defence of physicians and hospitals against the many claims for compensation and limiting the level of indemnities. The legal norms have begun to contain and request certain assessments before the beginning of the trial, certain limitations of the indemnities' value have been imposed and witness of experts and evidence of facts have been regulated (Robinson, 1986). The situation from Romanian health system can follow a similar course; the level of granted indemnities is a higher one for the economic and salary level being able to lead to the blocking of functioning of some hospitals and, as such, entire communities can be deprived of providing medical services. Even though the examples are not various, and the length of trial is a long one, it is important to regard them as a warning signal. In the middle of 2017, the mass-media has described the situation of a province hospital which has had to pay jointly with an obstetrician the amount of half of million Euros for a case of malpractice of 2009 (Sofronie, 2017).

Within the purpose of understanding the answer of the physicians to the "crisis of malpractice", the cultural and economic effects which this phenomenon has on the medical profession must be taken into consideration. The loss of the social status by subjecting the physician to a procedure of malpractice represents a severe hit on the "pride" and professional notoriety. Annandale acknowledges two comments of some physicians as response to the threat of malpractice: "patients have seen him as being together with God. People will never see their doctors as such (...). Physicians have never felt as a subclass of the society. We have always been the higher class of society. Now, there is a crasy schizophrenia in the medicine in which, on the one hand, you are an important group, you have obtained extraordinary quantities of skills. On the other hand, you do not want to cover yourself when walking and when you uncover yourself to see the name of a friend in a big trial and feel terrible" (Annandale, 2008).

In the review of the book Key Concepts in Medical Sociology written by Gabe and collaborators, (Gabe et al., 2004), several study directions of medical sociology are identified. Even though no clear explicit theoretical approaches concerning the concept of malpractice can be identified, certain aspects are important to be mentioned. The social modelling of health can be done analyzing the social dynamics which structures the demographic and epidemiological profile of health and disease, with approaches which emphasize in the analysis elements related to the type of individual development, life events and life cycle. The human experience related to health and disease includes 
discussions about the embodiment, risk and death. The economic, social and political structures contours medicine in a society which tends more towards occupations and professionalism, were we register the decline the medical autonomy. The reflections concerning the organization of system for the care of health will contain records, concerning the privatization, social movements, citizenship and medical malpractice (Chamba, 2006).

\section{Individual opinions of patients regarding...?}

For more than 50 years, the behaviours related with the disease have been researched empirically using mainly the quantitative methodology (Young, 2004). The inclusion of the qualitative research methods has raised new questions concerning the adequate method of each method of delimiting the complex problem represented by the humans' behaviours in front of the diseases (Norris, 2001). The modern social relationships are complex ones, include many levels of interaction: it becomes necessary to include the persons, institutions, as well as the interaction elements interests.

In the article of Winance and his collaborators, the analysis of complaints against the medical care is done from the perspective of the patients' point of view (Winance et al., 2017). Analyzing the experience of chronic diseases, Charmaz proposed the notion of "self - loss" to designate the transformation of identity related to the transformation of body caused by disease (Charmaz, 1995). This "self - loss", which is a specific pain, is characterized by a double breakdown: first of all, between self and body, and second of all, between the personal identity (self-defining by individual) and social identity (identity formed by the relationships with the others). Charmaz analyzed then the processes which allow people to maintain this breakdown (but to keep the identity of past despite the transformation of their body) or to establish a new unit (by the transformation of the identity in accordance with the new body modification induced by disease).

The disease can determine a permanent loss (in terms of functionality, abilities, autonomy or quality of life) for the person in question and depends on the way in which the person reacts and adapts to the loss. Focusing on the identity matter, this approach underlines the cognitive dimension of people relationships with their bodies. The body is a representation which people build based on personal experience. The notion of "loss" becomes pertinent for the analysis of which the body lesion represents for plaintiffs. In many situations, the notion of loss exceeds the "loss of self" and includes losses of other type (Winance, Barbot, \& Parizot, 2017). It is opened a way to repair the damage by the provisions of the civil codes.

A part of the patients has been designated and analyzed from the perspective of their litigious potential or predisposition to have such an attitude up to the level of behaviour (, suit-prone patients"). A part of the attention given to the relationship physician - patient in association with the medical malpractice has been headed towards the change or analysis of the physician's behaviour. It is assumed that the patients send a set of hints which guide the physician towards the use of a consultative style which focuses on taking decision and liability mutually. The patient's behaviour cannot be ignored in the attempt of analyzing or even reducing the impact of medical malpractice. Considering 
the importance of patients' perceptions concerning the body injury during time (negligence, mistake or otherwise), the attention of physicians focused on the recognition of patient such that he has approaches during consultations or treatments. This perspective is a common one in the medical community because the patients' stereotypes have been proved to be common in the medical practice (Wallen, Waitzkin, $\&$ Stoeckle, 1979). The features of the patients predisposed to legal actions can be divided in psychological and social demographic dimensions. The psychological features of patients, like anger, fear and rejection are some of the strongest psychologically motivating forces; other researchers have chosen the type of personality starting from the basis that it is most probably that, depending on its type, that a patient can address to the court in comparison with another. Other features taken into consideration have been the dependent attitudes and the lack of understanding of personal emotions. The social demographic dimensions specific to this type of patient are not fully described.

\section{The therapeutic relationship between physician and patient}

Depending on how rich and complex the meeting between the physician and patient is (at interpersonal and role level), the two parties are surrounded by rich and complex backgrounds. The claims and preoccupations of families, the values and expectations of society and some of the special matters of some social restraint, religious circles cannot be omitted. (Mount, 1990). All these are modulated in the specific setting of the hospital or clinic and are influenced by other members of the care team; today, the number of professionals involved in the process of care increased a lot compared to the moment of creating the initial Hippocrates medical model. The therapeutic relationship is influenced by intra-hospital policies, governmental regulations, requirements and documents requested by paying third parties (private or public insurance companies), legal limitations. To all these, it is added the possibility of some costs related to the occurrence of a medical malpractice. From this perspective, the patients and the physicians cannot be considered individuals who act freely against the influence of all the historical, social and institutional connections (Mount, 1990). All these influences can be considered constraint elements of an ideal, open therapeutic relationship.

Rayner brings into discussion the perspective of Parsons, taking into consideration the lack of trust in the physician manifested by mothers, as representative of their children as patients (their discourse is the basis of the ethnographic research of the article). The author emphasizes two extreme perspectives against which, he considers opportune an intermediary one. The first situation would presume the understanding of the therapeutic relationship as a "trade transaction" and the second one as a separation of the two roles: the physician would be the "professional" and the mother would take the role of "patient" as representative of the child (Rayner, 1981). This separation leads to a physician preoccupied with a discourse which contains the reasons which led to a severe evolution and with non-reparable lesions for the child and the mother will focus the "pleading" on the fact that the lesions have occurred during the period in which the child has been under the care of the physician. Even though the language and the way 
in which such a dialogue can take place in such a situation can take extreme forms, it might be more important for the understanding of the situation the start from the conventional sociological roles of the physician - patient relationship. Even though the researches of Parsons in the 30s have become "classic" and time has brought many critics concerning the applicability in modern world, the central idea remains current: the problem of health is intimately involved in the "functional premises" of the social system. Consequently, the patient is dysfunctional and the sick person, by occupying the role of "patient" receives the status of deviant. For Parson's perspective, the role of "professional", on the other hand, occupied by the physician, "combines the bealing technique, in the benefit of the patient, with the responsibility of social control for the benefit of company". Several critics claimed that in the concept of "professional role" and "patient role", the physician appears as technical expert, benignant and neutral, while the patient is passive and dependent. The current situation of the physician - patient relationship is one distanced from this division, in two roles: the patient is not a passive and "obedient" one anymore.

The article of Maseide is structured based on the opinion that the sociological literature concerning the medical practice targets mainly the therapeutic relationships physician patient which is currently described in terms as asymmetric relationship, cognitive conflicts and dominance from the professional party of the relationship. The unwanted consequences of the physician's power towards the patient are common elements to critics brought to this biomedical model of modern medicine; consequently, alternative models as social and psychological perspective have been developed. The understanding of nature and the role of power in medicine represents an insufficient and uncompliant perspective, such that an alternative vision of designing and understanding the power becomes necessary for an adequate medical practice (Maseide, 1991).

It is introduced the term of medical adequacy for reporting the process to the context in which the medical treatment takes place. The medical activity includes the regular use of a specific language and of other documents and symbolic forms. The understanding of language within medical specialty context, together with the cultural arbitrariness concerning the medical practice and competence, lead to the necessity of existing a local production of a social order or medical adequacy. The possibility of the existence of a mismatch between the cognitive contextual plans of physicians and those of the patients create a potential and real threaten to the medical conduct (Tannen \& Wallat, 1987).

The possibility of being sued for malpractice represents for the physician a strong enough impulse to comply or, in other words, to be adequate medically. This adequacy can be assured by clinical rituals and routines (called now protocols of good practice or procedures) and which will serve to obtain a normative order in the medical practice. It is important for physicians, mostly in the cases with uncertain prognostic, to be able to guide patients towards procedures which, even though are probably inefficient or even dangerous, are adequate medically. Even though a physician can be wrong, he must be secured institutionally. Pushing the medical practice to a routine or standardization will secure this medical adequacy, but it will have a minimum impact on what the physician - patient relationship means. 
The theoretical approach of Maseide is represented by the analysis of physician - patient interaction models, of incongruencies types (of competence or expectations) which can affect the practice, but of constraints which can occur in the everyday practice. The control model, which presumes a control of the physician within the therapeutic relationship by the power which he has by the professional status, does not accentuate the social privileges of the physician and the directive force on the patient. The focus on the potential asymmetry of competence created and maintained by the social inequality and social contradictions will not succeed in describing correctly the role of power in the medical practice. These approaches would indicate a concept of power which, first of all, would be an abusive one. Instead, the power is thought as necessary in the clinic and, in this regard, it is benignant. Thus, the physician can act as a competent person from situational and institutional point of view. By the discursive formats of medicine, the power of physician can produce knowledge, competences and practice models and generates a medical adequacy (Foucault, 1973). The relevant problems from medical point of view are achievements of the clinical practice, with the use of personal technologies and methodologies, based on medical reasoning and knowledges, based on the medical reasoning and knowledges and performed by the relational domination of the physician and by the institutional authority during clinical examinations.

Murray's and collaborators' article identify a situation in the case of Chilean obstetricians, considered similar to the Italian ones; the physician have the "feeling" that the lower number of malpractice complaints is related to the way in which the therapeutic relationship of physician - patient is built and the ease of communication between the two parties of the therapeutic dyad. It is about a private obstetric care and of the promise of a permanent availability from the physician. The personal phone number and the professional contact data are offered. These matters reflect the literature of the USA and Great Britain, reviewed by Annandale (1989), in his study ( Murray \& Elston, 2005). The litigious cases are considered rare in Chile and, when these occur, they receive a large media cover. The theoretical approach concerning the malpractice is discrete; the comments are related more to the perspective of structural organization of health systems.

The trust as basic element in the improvement of the therapeutic relationship was regarded as vital matter of the relationship between the providers of medical services and patients. The choice which the consumer exercises has been credited, more and more, as a method for the improvement of quality and efficiency of medical services provision. However, it is uncertain the method in which the increase of information quantity necessary to allow the users of health services to make choices in a market of public health systems, will affect the different dimensions of trust and the way in which the change of trust relationships will have an impact on the patients and offered services. The article of Fotaki brings some clarifications using an approach based on a theory that investigate the conceptual and material relationships between choice, trust and markets for the care of health, within the context of National Health Service of Great Britain (NHS). The patient's choices will have involvements on the system, organizational and interpersonal trust. The transfer to marketing in the public health services would lead to an excessive dependence on the rational matters and related to 
cost of trust in the detriment of intrinsic, relational and social matters. It is developed an alternative psycho-social conceptualization of trust which is focused on the central role of diseases. In the public British system, the choice has been or is perceived as absent from historical point of view (Fotaki, 2014).

Mulcahy (2003) ${ }^{1}$ guides us on an important moment concerning the introduction of some subjects as "complaints" and "consumerism" in the papers intended to students from the field of social sciences. Before 2001, these subjects did not exist in the list of discussed subjects and changes occurred subsequently. The Mulcahy's book examines the social and legal dynamics of disputes between physicians and patients, based on many studies performed by the author. The complaints concerning the medical practice are an example of the consumers' activism which has received a little attention from the researchers, even though the raised problems refer to debates about the power related to the professional type of the physician, the dynamics of the physician - patient relationship, the concepts referring to rights, the trust in the physician and the impact of law on the daily human behaviour. It is the moment when the American government has declared that it will reform the approach and the laws regarding the clinical negligence and the system for the management of complaints. The analysis detailed in the second half of the book identifies the inherent tensions to the processing of complaints as a reflection of the public debate between politicians, bureaucrats and medical professional elite, concerning the role of physicians in the society (Meerabeau, 2006).

\section{Multifactorial perspectives - systemic problems}

The social sciences have analyzed the problem of complaints related to the medical treatment from various perspectives. Some of them focused on the way in which the physicians and their professional organizations react to the increase of the number of litigations (Barbot \& Fillion, 2006). Others have analyzed the management methods of medical errors and conflicts occurred within the medical care (Bosk, 2003) or the involvement of economic costs of receivables occurred as consequence of a medical malpractice (Danzon, Pauly, \& Kington, 1990). Another perspective is the one which is focused on the analysis of complaints and the way in which these would contribute to the improvement of the medical care quality and of the dialogue between physicians and patients (Allen, Creer, 2000). The quantitative researches have emphasized the low rate of judicial actions of patients concerning the harmful events and, among the plaintiffs, the sub-representation of the most vulnerable patients (Burstin, Johnson \& Lipsitz, 1993). The difference between the number of harmful events and the number of cases has led to questions related to what the complaint process means for patients. Some studies focused on the difficulties which the patients face when they call for the hospitals' services and when they face the asymmetrical competences and status which can be exercised against them (Mulcahy, 2003).

${ }^{1}$ In the book Disputing Doctors: the Sociolegal Dynamics of Complaints about Medical Care, Maidenhead: Open University 
The discussion about the phenomenon of medical malpractice can be centred on the explanations of the relationship between medicine and law in terms of two models: "economic" model, used first of all, but not exclusively, by the supporters of a socialized medicine and the "multifactorial" model, which can be used to express a variety of affinities, but which presumes a plurality of factors which can explain the increase of number of deviations from the practice standards.

The strict existence of a model of economic type was fought by Titmuss (1973). ${ }^{1}$ The fact that NHS (Public Health System of the United Kingdom) is not "abused" by the unjustified requests of patients, without a market price which can regulate these requests, represent a reason. This matter, predicted by some economists, offer a support for the thesis that patients do not perceive the supply of medical services as a trade transaction (Titmuss, 1973). Since then, the author proved that there were many evidences that there was a high level of use of some useless medical procedures in the USA. Moreover, the reimbursement mechanism of fees for services leads to an excessive use of some potentially dangerous forms and often inefficiencies of drugs; however, it is not clear if there is a direct relationship between the number of useless practices or procedures and the level of litigations in a certain state. This conclusion has as basis a comparative analysis of health systems, American and British, at the crisis moment of '70s.

Most of the comments concerning the "malpractice crisis" of " 70 s in the USA presents multiple reasons of its occurrence contouring a multifactorial model. David Mechanic offers a comprehensive analysis, even though one is based on the sympathy towards the medical profession. For him, the problems related to malpractice are symptoms "of some deep problems in the medicine practice, in the insurance system and in the structure of our unit". He lists the following factors:

- increase of specialization in medicine and increase of public expectations towards medical care.

- high chances of human error in modern medicine, more and more technologized

- ambiguity of medical standards in front of standards requested by courts

- refusal of medical insurers to appeal the complaints with small values

- fragmentation of the care process which leads to the destruction of trust in the relationship physician - patient

- the increased accessibility to the medical documents used by plaintiffs

- the increasing refinement among the medical consumers and a higher accessibility to legal services (Mechanic, 1976).

These factors are accompanied by a higher increase of the disbelief degree in the society which, concerning medicine, takes the form of a "strange ambivalence" regarding the medical care: on the one side characterized by high standards as performance and

\footnotetext{
1 in the book The Gift Relationship: From Human Blood to Social Policy
} 
technology and, on the other side, accompanied often by unreasonable expectations. There is a strong feeling of dependence, but also a quasi-permanent critical attitude. Mechanic develops the thesis about the relationship between the money offered for the service offered by the physician (FFS ,fee for service") and litigations starting from a lecture of the Freidson's book ${ }^{1}$ The payment of a fee for a medical service brings a modest influence to the physician - patient relationship; the competition between physicians, the transfer of payments from some immediate ones to some intermediated by insurers, as well as the direct perspective of a payment of fee affects the way in which the patient and the physician report. From the analysis of Mechanic, it seems that it is missing the observation that patients have become more "consumers". It means the clients' control represents, from consumers perspective, a reaction of the middle class which probably originates from the assumption that "health" and not only "the health care" is purchasable (Rayner, 1981).

Duane Stroman performed an analysis ${ }^{2}$ from a systemic perspective in which the malpractice phenomenon is a process indicator and it is analyzed as an individual phenomenon. The deficiencies of the medical care system of USA are well documented in time. At general level, for a nation which is preoccupied intensely with the increase of the proportion of amounts from the national gross product spent on the medical care, the USA obtain a relatively low yield concerning the indicators of the health status, like the infantile mortality rate. More exactly, there are evidence that many medical needs are not fulfilled, especially among the poor, black people and in the rural areas; the quality of offered care is unequal (many malpractice complaints are the proofs). A dominant fact within the medical services is represented by the financing system which encourages the performance of some useless interventions and favours the appeal to the high technology for curative medicine in the detriment of primary medicine which would have a preventive, primary function. The book objectives from the perspective of social responsibility would be the examination of these deficiencies, the evaluation of the responsibility for it and the enunciation of some proposals for change (Ham, 1980).

\section{Economic problems - costs of the services and the malpractice insurances}

Tomes' vision is one related to the challenges brought by the technological development in medicine and to the higher economic costs. The $80 \mathrm{~s} \mathrm{decade} \mathrm{is} \mathrm{eloquent,}$ it is outlined as a marking one from this point of view. The results of the change were many and threatening: the apparent uncontrollable inflation of costs related to medical care, the surprising increase of costs as consequence of the medical malpractice processes, the public controversies concerning the use of medical technology to extend the lives of patients or of those with severe disability. A part of these controversies is still maintained and, many times, is the agenda of media institutions. Maybe the most concerning of all, at least from the physician's point of view, are the challenges brought

\footnotetext{
1 Profession of Medicine

${ }^{2}$ Stroman D. (1976). The Medical Establishment and Social Responsibility, New York: Kennikat Press
} 
to the independent traditional practice by the one which presumes the direct payment for the medical services supply (even now, the medical corporations use two large types of clients categories: FFS - Fee-for-service and PP - Pre-paid). The direct payment by the patient of a medical service causes a change in the attitude and requests of the patient for a medical document, qualitative and safe; moreover, a result conditioning may occur many times. The Reagan administration supported such practices regarded initially as "heresies", as pre-paid group medical practice and began to use the professional organizations to establish limits of federal reimbursements for the costs by Medicare and Medicaid services. At the same time, in the field of health, it was acknowledged the increasing presence of profit-oriented corporations; this aspect promotes a care both among the physicians and civil society (Tomes, 1985).

An essential matter of the crisis from the 70s - 80s, which affected directly the physicians, but which passed further to the patients by the payments for medical services, was represented by the cost of medical practice insurance for the eventual situations of malpractice, costs that became higher and higher. In some cases, the insurance premiums for malpractice increased $500 \%$ in the middle of the seventies (Morrow, 1982).

The historical perspective offers us some explanations concerning the evolution of the phenomenon in an expansion moment. Such "rate increases" were attributed to the rising will of patients to sue physicians, lawyers' practice of charging fees only in cases completed successfully (which had as affect the orientation towards profitability) and the grant of some higher and higher indemnities to courts. Between 1967 and 1975, the payments which exceeded 25.000 dollars, performed by the malpractice insurance to patients, have increased with a rate higher than $20 \%$ per year and, in a case, dr. John Nork has been made liable requesting him a record damage of 3,7 million dollars (Law $\&$ Polan, 1978). These authors argue that this increase rate has had a lot to do with the cash flow and investment problems of insurers than with the patients' claims.

However, the claims have been usually awarded to the "bad apples" from the medical occupation: certain physicians have been considered to be more "inefficient" than others and these would represent a higher percentage from the proportion of payments for insurances. It is an obvious relationship with the physician's incompetence. It has been argued that the insurance costs can be reduced by the identification of this "bad apples" and, for this, the reform efforts have been led; the possible option has been the rehabilitation or their interdiction to practice. A different impulse has come from another matter of the malpractice crisis. In the litigious atmosphere that encompassed the medical services in the American system knew, it has been acknowledged that the medical personnel of the hospital would be collectively responsible for the actions of their colleagues (Stimson, 1985). Under the jurisdiction of a joint commission on accreditation of hospitals (,Joint Commission on Accreditation of Hospitals"), the body which targets the admissibility of physicians and hospitals for medical insurance, the medical personnel is mutually responsible for the periodical evaluation of professional qualifications and evaluations of colleagues' performances and the civil liability could result if this evaluation was permissive, relaxed. 
The Morris' article is a response to the review of a book which analyzes a common subject for various health systems, the alarming increase of the number of C-sections. The review performed by Anna Neller (Neller, 2015) reproaches that he did not see the focus on the malpractice phenomenon. It is discussed the danger that the sociologists are not trained enough to offer pertinent opinions concerning medical treatments and, especially, they cannot measure the efficiency of medical treatments or identify potential complications of alternative treatments (Morris, 2015). Even though, in this response, a theoretical direction concerning the medical malpractice cannot be precisely identified, the starting point of the comments have $\mathrm{n}$ economic motivations. The amounts spend in the USA for the assistance at birth are higher than those spend by any other state; however, the results are ineffective and it is proposed the reform of the compensation system for body lesions to a model based on results which reimburse all the lesions occurred with the occasion of birth separately from the investigation concerning the medical malpractice.

The important matter that was drifted from the view exchange of opinions is that the observation of a certain type of medical procedure (in this case the $\mathrm{C}$-section) can be used as a lens by which various organizations can contribute to the modification or improvement of some medical practices which, until now, were conceptualized only as a choice of the clinician and of the patient. Various international bodies and professional companies (for example The American College of Obstetricians and Gynaecologists, The Society for Maternal-Foetal Medicine, World Health Organisation) raised the problem of the unjustified high number of this type of procedure, the rates of complications and other problems of medical and social type. "There is no doubt that any connection with the women bodies (and mainly with the mother women bodies) is political" (Morris, 2015).

The review of the book Medical Malpractice: Theory, Evidence and Public Policy published by Danzon, in 1985, declares the principles which have been its basis; these have been the economic ones which have promoted the increase of number of litigations in the middle of the 70s in the USA, known as the period of "malpractice crisis". The system by which indemnities are obtained as consequence of the negligence during the practice of medicine is seen as a system which brings a "control on the quality" of medical document. Discussions are raised about the relationship between the legal care standards and the "optimal" ones, about the type of "defensive medicine" and about the proposal of a new system which regulates and reduces the compensation level. The conclusion which completes the analysis of book declares that it could not be possible to answer to the most important questions about malpractice (Fenn, 1987).

\section{Orientation towards the quality and safety of the medical treatment - monitoring and regulation}

Another perspective is the one related to the quality of the medical documents within some larger processes for the monitoring of services quality. Waring and collaborators' articles follow more a historical approach, on an axis of time without offering sociological explanations circumscribed theoretically. At the beginning of $20^{\text {th }}$ century, the American physician Ernest Codman asked physicians to track the progress of each 
patient and, also, to analyze the causes of each of the poor therapeutic results (Codman, 1917); this method of monitoring can lead to the creation of a list concerning the error sources in medical conduct. Over time, many important progresses in the field of knowledges and medical practice have been, somehow, prohibitive by a wider policy of professional power, especially if new knowledges would question the autonomy and lawfulness of occurring medical occupations; this theme is consolidated by many contemporary studies concerning the medical regulation (Rosenthal, 1995). Starting from these initiatives, malpractice trials are begun against the physicians who have performed errors; initially, these have begun to be signalled in USA and their number has increased in time. The interest in quality and safety date since the beginning of $50 \mathrm{~s}$ and until the 80s. It took place simultaneously with the evolutions from the modern medicine, including the explosion of advanced technologies of diagnostic and treatment, advanced procedures, new pharmaceutical products and the occurrence of some modern disciplines, like intensive care, emergency medicine and new surgical subspecialties (Le Fanu, 2011).

An interest subject targets the exposure of the method in which the elite of professionals has tried to isolate the physicians from the managerial intervention in treating complaints. The standardization concerning the treatment of complaints at local level of a medical institution did not take place until the middle of 1960 and even then, it has been a preference for an informal approach.

The "scandals" from hospitals since the middle of 1970 have led to the occurrence of some committees which manage complaints but, the most comprehensive reviews consisted of defining the way in which the concession from the level of medical institutions succeed in preventing tougher actions. However, for many years, the process for the introduction of complaints included only physicians and not all of the initial practiced recommendations. There has been a minimum monitoring of complaints and a less use of this information to improve the medical practice. A theoretical approach includes the study of complaints reported to the medical conceptualization of lacks and patients' claims as consequence of some damages brought by negligence. Even though most of the lacks is caused by the failures of the systems, the legal structure encourages the perspective of an individualized guiltiness and the medical systems do not adapt easily to justice actions introduced by groups. The medical experts remain considerable as power in defining what is "deviant" and the lawyers are interpreted as "forbidden intruders" (Meerabeau, 2006).

The historical perspective by which it has been tracked the evolution of quality and safety of medical assistance movement identifies four phases of development. It is stated that only during the last three decades the subject has gained a political impulse on the international scene and this factor has led to researches in this field. The quality and safety in the field of health are central sociological subjects; medical sociologists face the dilemma of the necessity to advance towards a sociology of quality of safety or the development of a sociology for medical quality and safety (Waring, Allen, Braithwaite \& Sandall, 2016).

The number of institutions and agencies which take care of the social control of medical profession increased progressively. Some reasons have been descried for which 
the American physicians have succeeded in recognizing the problems of conduct and competence deficiencies of physicians. There have been some directions in which, new types of control on the medical occupation, could develop by the occurrence of many difference bodies which could be responsible of this control, both within and outside the profession. In comparison with their British counterparts, the American physician of the 1970s has become a professional body under the regulation power of a wide range of regulation entities (Stimson, 1985). This matter represents an attempt to exercise the control on medical activity, in a presumed free space, defined subsequently as market economy of medical care in which the influence of law becomes higher and higher. An additional matter is the importance of financial societies in the process of medical care. The phenomenon is facilitated by the fact that the majority of American physicians have begun to work in institutional or organizational settings (for example, as employees, members of the corporative institutions or beneficiaries of the indemnities performed by third parties - insurance systems) which increase the possibilities of activity supervision. Many features of the physicians' behaviour are monitored by the Medicaid and Medicare systems, as well as by insurances; the targeted companies have as primary objectives to limit the costs of medical and surgical services (Pontell, Jesilow \& Geis, 1982). The organizations for the assessment of services analyze the costs of services financed federally and offered to patients to ensure that the supplied services are necessary from medical point of view, are supplied at the right prices from economic point of view and fulfil the quality standards recognized professionally.

The initial problem was the identification of the body which had to assume the responsibility for the evaluation and endorsement of physicians' competences; this role was disputed between the authorization councils of the state and those of the medical professional societies. The license becomes the responsibility of the state and the public council has received the responsibility for the disciplinary evaluation and the boards of directors are the only bodies with legal authority to revoke or limit the permission to practice medicine. In New York, the board of education has the responsibility of granting licenses for nineteen various occupations involved in the medical care. Moreover, this board is also responsible for other occupations, like accountants, social workers, professors and architects. The rules concerning the professional violations are encoded in the public rights and the offences include the limitation of occupation practice while the person is under the influence of alcohol, drugs or there are physical or psychic diseases, disabilities, among which narcotic, barbituric, amphetamine, hallucinogen addictions or other drugs which have similar effects. Also, it has been drafted a disciplinary investigation procedure for physicians.

The learning processes concerning the notions of malpractice, the recognition of potential litigious situations as well as the gathering of some skills which reduce these risks are the subject of some discussions within the medical occupation. These educational matters are part of the wide spectrum of medicine evolution from the professional's point of view. The sociologists appeal, repeatedly, to the notions of altruism, bureaucratization and personal interests in their effort to explain the changes at level of profession in the contemporary society. 
Freidson defines an occupation as "a set of institutional regulations which allow the members of an occupation to build a life which they control the personal work" (Freidson, 2001). Gorman and Sandefur (2011) state that these institutional regulations refer to four central attributes: the specialty knowledges, the technical autonomy, the engagement to serve other as well as the obtained incomes and status (Gorman \& Sandefur, 2011). The altruist reporting of the professional project has its roots in the papers of Durkheim and Weber, who have represented the group of physicians as occupational communities united by a vocation feeling or engagement against the service offered to clients or societies.

Pellegrino defines the altruism as "that feature which a person has to take into consideration the others' interests when they use power, privilege, position and knowledge" (Pellegrino, 1989). Barber goes further than this and he states that a "primary orientation towards the community interest, rather than to the individual selfinvolvement" is one of the defining features of an occupation (Barber, 1963). Wilensky agrees, suggesting that the "devotion towards the client's interests more than to the personal or commercial profit should orientate the decision when the two are in conflict" (Wilensky, 1964). From altruist perspective, the archetypal institutions of an occupation (containing long periods of education, ethical codes and supervision and discipline mechanisms) function to encourage and support the vocational engagement and to reassure the society that the medical occupation and persons which practice it are proficient and trustful.

In a study performed by the interview of 998 physicians in general medicine from the Wales, it has been identified an altruist engagement against the study and improvement of bureaucratic requests for the reporting of information concerning the incidents of medical practice, and also resentments concerning the changes from the occupational pack of the general medicine practice. The comments suggest that the bureaucratic evaluation of physicians has installed a series of formalized rules and procedures which have absorbed the resources in many ways, but which have not succeeded in identifying the malpractice or in facilitating the learning. The dysfunction, according to some comments from this study, is given by the fact that the official evaluation processes have not been really determined by the intention of improving the learning process or identification of malpractice, but rather by the will of reassuring or at least satisfying the requirements of public programs and policies. There are, as a physician has explained, "other imperatives than those purely educative". Another one explains the fact that it would be better to "exist an informal discussion without too many documents; the idea is that the Government will not bear anymore this thing". "The entire process", explains another one, "is generated by the professors from the ivory tower who try to answer to a political agenda which has nothing to do with the way in which we really learn" (Entwistle \& Matthews, 2015).

The safety of patient is designed in a strong interrelationship with the one of malpractice. The current reforms concerning the safety of patients offer changes concerning the regulation of medicine. Based on the existing literature, it is stated that this political agenda represents a new border in the relationships between the medical and the managerial practice, offering the managers a disciplinary expertise within health services which provides knowledges and lawfulness to investigate and control the 
medical performance by the procedures of reporting the incidents and the analysis of the causes which lead to the unwanted events. This tendency was followed in Romania by recent incorporation, in 2015, of the National Authority of Quality Management in Health (ANMCS); this structure took over the specific responsibilities by the reorganization of the National Commission on Accreditation of Hospitals, a new body within the autochthonous medical system.

As in the case of other organization, the physicians oppose to the managerial prerogatives by the attempt of undermining and "capturing" the components of reforms (including those which increase the regulations concerning the assurance of quality and safety). It is a phenomenon described as an "adaptive" one by which the physicians attempt to maintain the monopole and limit the government regulations. It is however considered that this process could signal the future "modernization" of medical professionalism within a larger context of reform from public sector in which the medical culture and practice are more and more internalized. This thing leads to self-supervision, self-management or "self-governance" forms, removing eventually the need that certain external groups manage or regulate explicitly the practice within the medical occupation (Waring, 2007).

The number of articles which analyze the regulation of the medical occupation in Europe seems a lot smaller, maybe because the process followed the American one. An example is offered by an article concerning the phenomenon suffered in Belgium. It is stated that the medical occupation suffered obviously a lack of internal coherence in the $19^{\text {th }}$ century. The interests and objectives, for example, of the Royal Academy of Medicine, of the province medical councils and of the Medical Belgian Federation were not homogenous. Two general tendencies have been described: the legal unification of the occupation and its institutional development. Another tendency was focused on the impact of professional associations in the field of medical education and in the control of the medical documents from the practice point of view (Schepers, 1985).

It is possible that the Belgian physicians has not had an important role in the formulating of new policies and in the reforming of medical institutions. Few comments have been identified concerning the specific law. Various examples of quotes have occurred concerning the malpractice actions of some irresponsible physicians. The surgeons were content about their new legal status but, some physicians did not have their privileged position and would have preferred the prior hierarchical structure in medicine (Pollenuss, 1813, p. 62). ${ }^{1}$

\section{The change of physicians' autonomy paradigm - Limitation of physician's "power"}

Starr $(1982)^{2}$ analyses the past and present tendencies regarding the role played by the physician and enunciates a threatening conclusion. "In the $20^{\text {th }}$ century, medicine was the heroic exception which supported the decrease of traditionalism to independent professionalism". But,

\footnotetext{
${ }^{1}$ Essai sur le disordre actuel en medecine et sur les moyens propres a le faire cesser

${ }^{2}$ In the last chapter of the book Social transformations of American medicine
} 
his analysis, suggests that "the exception can now be brought to conformity by governmental rules". The special historical conditions which have allowed physicians the restraint of competition, the limitation of external regulations and the professional training according to priorities seem to give the lead to new tendencies; these are permissive for the occurrence of some strong third - party interests, the government and the company / organization which offers the service. It is heading towards a limitation of the physician's autonomy. Starr's conclusion is: "Excepting the case in which it would be a radical change within the American economic and political conditions, during the last decades of the $20^{\text {th }}$ century, it could exist of period of time marked by the diminution of resources and autonomy of many physicians, volunteers, hospitals and medicine schools" (Starr, 1982).

Starr's book is characterized by the synthesis power and by the evaluation in due time of the crises from the American health system, observed in the "70s and continued in a certain extent now. As such, his book is obliged to have a significance and a long-term impact on history and sociology. As a synthesis, the book is remarkable, but it does not seem probably that it would become the standard reference concerning the American medical history, as some enthusiasts would have suggested. There are also some subjects which receive insufficient explanations, like medical malpractice and physicians' relationship with other occupations from the field of health. But such failures do not destroy the assembly power from the interpretation of Starr (Tomes, 1985).

The Charmaz's article presents a series of courses of Open University which approaches the field of medicine from the perspective of social sciences; it is observed the occurrence of some reference to the problematics of malpractice within one of he presented essays ${ }^{1}$ It starts with the proposal that the resolution of current problems in the health care means to be based on an ample strategy which contains all the medical disciplines which are directed to problems specific to the health insurance. Moreover, the authors suggest that no matter of the proposed solutions, these will produce "problems".

The authors presume that the same problems re-occur despite of the social and historical diversity which the organization of the care systems enclose. The discussion abovementioned begins from the fact that the visibility of problems depends on the particularity of a care system. These authors succeed in getting closer when they say that NHS is, above all, "a national hospital". It is also a system dominated from medical point of view, as long as the members of the board of directors are selected rather than being chosen from the communities to which they belong. The relative lack of laic persons' power (not belonging to the medical community, patients) serves for the improvement of medical institution power. In comparison with the USA, the authors consider that the British physicians which work in NHS have more clinical freedom to treat patients, as they want, depending on the principles and knowledges which they have. The physicians of the USA can be somehow constraint, but not by their professional councils or by the colleagues. The endorsement from them are considered "cosmetic", without force. The constraints are imposed by regulation groups which

${ }^{1}$ Caring for Health: Dilemmas and Prospects 
analyze the compliance of diagnostic and by the increase of number of malpractice processes which are more real and stressful in the current practice (Charmaz, 1986).

From a sociological perspective, the medical crises of malpractice, in the United States, can offer an opportunity to explore the response to medical occupation to the threatens on the practice autonomy. The way in which the physicians and jurists have responded in time can be seen in the content analysis of various articles from specialty journals and from the reflection from media; an increased attention is given to the development of a better report with patients, supplying many, credible information and involving the patient in taking the decisions concerning the care.

A special expression of the health "crisis" of the USA from the 70s is represented by the dramatic increase of malpractice litigations; this matter can be seen as an indicator of the threatens to professional hegemony and self - control of this occupation (Annandale, 2008). The reforms from the medical system of that date have led to changes in the physician - patient relationship, appealing so the patient receives more information and begins to have an active role in taking decisions concerning the treatment. The phenomenon of malpractice can be seen as one which promotes some of the changes which, a lot of sociologists observed to be essential for the improvement of the patients' care. The improvement of the therapeutic relationships, generally, can lead to a decrease of number of litigations, being in the centre of such a strategy. A second aspect of this situation is that any strategy used for the increase of satisfaction level of patients can be used to mask the possible errors of clinical practice.

A paradigm started from sociological theories is difficult to be identified even in larger papers which deal with the phenomenon of medical malpractice. Such an example is Merylin Rosenthal's book published in $1987^{1}$. The discussion is a comparative one, concerning two health systems, the one from the United Kingdom and the one from Sweden. The emphasis is on how a complaint is approached from procedural and organization point of view. The main role falls on the collegial structure of physicians, GMC - General Medical Council, respectively Swedish Medical Responsibility Board. The review published in Sociology of Health and Illness acknowledges the weak points of the book. The introductory presentation of sociology of occupations is somehow superficial. However, when sociological problems are resumed in the last chapter, the different methods by which the medical occupation exercises and holds the power are discussed in an attractive way. The discussions targeted the way in which the medical occupation succeeded in keeping the power and autonomy, both in Sweden and in Great Britain, despite the fact that it is a paid service from personal funds or one within a public contract (Stacey, 1988).

\section{Physician - patient communication}

The communication with patients represents an important matter, mostly in the situation of severe diseases or in the case of unfavourable news; the perspective of

${ }^{1}$ Rosenthal M (1987). Dealing with Medical Malpractice, the British and Swedish Experience, London: Tavistock Publications 
Taylor's article is limited to the oncologic cases and especially to the situation of mammary cancer (Taylor, 1988). The central event against which it is done the analysis is the initial communication of diagnostic. It is attempted the identification and the method in which it is implemented an organized system of policies and strategies for the disclosure of diagnostic; even though this duty can fall in a work routing for physicians, it is characterized as a difficult and unpleasant one.

One of the fears recognized by physicians is the risk against the eventual potentially litigious practices for malpractice; for example, if a patient is discovered with cancer and he declares subsequently that he has not been informed about all the options of possible treatment. The study is a qualitative one, of ethnographic type, presenting discussions within the therapeutic team, between senior physicians and residents.

In comparison with many sociological studies which follow the way of transmitting bad news, the emphasis of this report was on the person who communicated the news, rather than on the patient who received the news. Three phases are identified: preamble, confrontation and spread of bad news. Four strategies are used to spread the message: evasion, dissimulation, approval of uncertainty and truth. This report suggests that the event of communicating bad news is perceived by the physician as a stressful one. As response, the physicians find complex methods to transform this duty in a routine (Taylor, 1988).

The improvement of didactic matters includes ideally the perspective of both parties. It is necessary a method in which this information can be useful for those who want to improve the communication between patient and physician. For example, the patient's education, the informed consent, the public discourses and regulations obtained a special importance in the medical care of North American in the 1980s. it is emphasized, more and more, the importance of patients' rights and the patient's involvement in taking medical decisions. If the objective is the open communication between the physician and patient, then the physician's preoccupations cannot be ignored. It can be easy and familiar for some sociologists to explain the apprehension of information by the patients only from the perspective of physician's power and it can be contoured as the result of a lack of professional responsibility. For sure, this distribution of power plays a certain role. However, this study suggests that this reason cannot be enough to explain why physicians adopt, maintain and transfer a certain communication policy.

Second, the way in which physicians have chosen a communication policy and which social systems encourage and support each philosophy needs a careful analysis. The medical education, the modelling of physician's role and the reward system from the hospitals provide valuable hints. Eventually, the communication policies of physicians should be seen and evaluated (Taylor, 1988).

The article wrote by Rayner brings forward the modification of communication between the physician and patient in a new perspective, different from the usual one until that moment; the medical perspective and the care one is quickly replaced by a legal one. One of the interesting features of the dialogues between a cardiologist and a mother is the way in which a complaint, which refers to a treatment, is transformed in 
the discussion of the legal basis of the mother's claims and their viability, in her special case, in front of the court. Despite the few sociological researches about this matter of conflict, the introduction by a mother of the legal problem against the physician's action on her child cannot be considered unusual: the general problem of malpractice is one of the central matters of policies of USA in the 70s, leading, among others, to an explosion of the malpractice insurance premiums, to physicians' strikes and to a defensive attitude from the medical occupation which has reflected in a noisy lobby in various states to modify the legal process (Rayner, 1981). Other associated phenomenon would result from the vulnerability of profession to the legal action: the practice of a "defensive medicine" - by which physicians use useless diagnostic procedures only to "cover" themselves, as well as "the abandonment of patients" - the refusal of physicians to treat them in situations with potential litigious circumstances or their repeated transfer to other services or physicians (for example, under the legal or procedural "cover" of the competence levels or technical equipment). The detailed analysis of these matters can bring important information.

The Lupton's article regards only tangential the problematics of medical malpractice, but he brings into discussion the change of social position and status of medical occupation and the extent in which the consumerism has entered in the relationship of physician - patient. To approach this subject, it has been performed an empirical study using semi-structures interviews, deeply, with 20 physicians who live and work in Sydney. Three major matters are discussed: the extent in which the social position of physicians has changed, the impact of consumerism in the medical practice and the qualities of a "good" physician. The involvement of this data for the theorization of contemporary medical practice type, of power and status of professionals are explored, referring especially to the perspectives offered by the theory of Foucault.

An essential matter is represented by the understanding by physicians of what their patients want and the way in which these conceptualize an adequate medical practice; an accent is on being a "good communicator", on empathy and on the need of offering the patient the opportunity of assuming a higher "responsibility" by the spread of the uncertainty which he feels (Lupton, 2008).

\section{Media impact - press and public reaction}

The American medical profession has received, also, a bad publicity by the failure to discipline their members. Some cases of the 70s draw the attention of the audience to the problem of malpractice and damages brought with the occasion of practicing the occupation of physician. The first of these cases has referred to Dr. Max Jacobsen who has been the physician of the president Kennedy. The Jacobsen physician has had a lot of rich clients anchored in the "trend" of those years; the therapeutic ideas and options of the physician were unusual concerning the therapeutic benefits of amphetamine. The treatment had, in some case, terrible results (Derbyshire, 1974). He was accused of the irresponsible prescription and improper use of such drugs. He was excluded from the national medical society, but the professional organization did not have the power to prevent him to practice privately and in his case, it was directed to the public disciplinary council. 
This period has seen, also, the occurrence and development of a critique audience. In comparison with Great Britain, the consumer's requirements become more explicit and more significant in the attempt of determining the quality and type of requested medical care. This critical consumerism has been developed further in the 70s. It was more and more present in the critique publications related to limitations and failures of modern medicine; these are familiar during the periods which followed. It is developed a form of strong assessment of consumers from the medical field which is emphasized by guides of patients concerning the medical care and patients' rights. The appeal to the patients' rights manifested by the support groups of patients led to an increasing interest for alternative forms of medical care and additional forms for promoting the health. The American medicine confronted, more and more, with an analysis about personal performance. As Starr says, "For the first time, the American physicians confronted simultaneously with a serious challenge concerning their political influence, their economic power and their culture concerning authority" (Starr, 1982).

Until relative recently, the individual choice has not been a priority in NHS (public British system) and trust has been taken a present parameter (Gilson, 2003); physicians have been obliged to observe the rules of professional conduct and it has been assumed that everybody, as a unitary professional body, are trustful. A series of public scandals which have involved the public health system have raised a series of questions concerning the quality in the field of public health and even have announced a failure of the system in England (Quick, 2006); also, questions have been raised about the utility of an unconditional trust in an occupation which is self-regulated. Moreover, "relatively isolated cases have been handled to build an exaggerate fear against the possibility of medical malpractice on a wide range within NHS" (Brown, 2008). By the transformation of patients in informed consumers, it has been assumed that it is obtained a reduction of the physicians' power and an improvement of the care quality. The rational perspective of such reasons is simple: the supply of information to patients allows them to request a certain treatment where the providers of health services will march to the disclosure of information concerning their performance or they will even attempt an improvement because, otherwise they will risk the closing of the sanitary unit. Offering to the NHS patients the free choice of the place where to be treated, when, where and how, it would have been suggested that it is obtained a more responsible care and even to reduce the importance of interpersonal trust, which this vision equates with dependence (Davies \& Rundall, 2000).

The introduction of clinical governance within the National Health Service of Great Britain dates since the publications of early policy of the labour government, during 1997 - 1998. The development of these documents can be understood within the context of the increase of litigations costs, of awareness of large variations of care standards, of the basic economic problem referring to the limitation of resources and increase of request for health services. The concept presupposes the monitoring of some important parameters of medical services (including data about mortality, morbidity, nosocomial infections and other sensitive subjects); this set of indicators are reported regularly and have as purpose the increase of care services quality.

The conceptualization starting from this direction has disclosed that the most pertinent problem, according to many analysis of clinical governance formation, is the need to 
restore the public trust in NHS (Alaszewski, 2002). The situation of trust both in the health systems and in the physicians as professionals continues to be a problem which needs a deep analysis. This accent concerning a "trustful" NHS has become, obviously in the legislation itself, and in the literature, which supports that the "interest for clinical governance has occurred because the individual professionals have betrayed the audience trust". The proofs of such betrayals include the series of "catastrophic failures in the diagnostic of bone tumours in Birmingham, the pediatric heart surgery in Bristol and the cervix screening in Kent and Canterbury" (Freedman, 2002) which have occurred at the end of the 1990s. The removal of the organs from the deceased patients, without the consent of the next of kin, which has taken place at the hospital Alder Hey of Liverpool, has completed this list of "dysfunctions". Especially, the Bristol case has been described as a "milestone in the development of health services and social care in the Great Britain" (Alaszewski, 2002), because its status of institution with high reputation and the similarity of findings of the subsequent public investigation with the reports concerning the heart services from Royal Brompton, Harefield and Oxford, has been considered an emblem of many endemic deficiencies, of the system, generally. The presentation method in the media of some relatively isolated cases can be considered manipulative to build an exaggerate fear concerning the possibility of medical malpractice on a wide range within NHS. The attention which must give to the media, as social mirror, whether of how manipulative or without loyalty it would be, must be adapted to the analysed situation.

The problem of trust reduction is extremely multi-rooted, more complex and spread than the simple incompetence, negligence or malpractice of some physician seen separately. Consequently, the avoidance of future dysfunctionalities in NHS could help to the slowdown of the trust decline, but not enough to blow over which represents a deeper tendency (Brown, 2008).

The review of Horowitz R.'s book, In the Public Interest: Medical Licensing and the Disciplinary Process (New Brunswick: Rutgers University Press) approaches themes which are current for the media from the last years. The mass-media and the legal system have begun to influence the public interest towards the organizational structures of medical profile and, also, it influences the discourses and the way in which various bodies supervise the medical activities. For example, mass-media draws attention concerning the inefficient complaint on medical management forums and the lack of disciplinary action on the physicians after the complaints enunciated against them. These matters have become a problem in the attention of the audience and, subsequently, legislative changes have been promoted (MacBride-Stewart, 2014). Within conceptual terms, Horowitz notes that there a lot of practical problems in the practical implementation of the democratic governance forms: difficulty for the involvement of audience, the fragmentation and orientation towards regional of the management bodies, the challenges brought by the principles of efficiency of medical practice and tensions related to the individual intimacy, community and scientism. A substantial critique is addressed to Elliot Freidson who says that the medical occupation needs a strong medical community; the promotion of the social closure "narrows the professionals" who act from the perspective of public good and, thus, it would work against the democratic deliberative processes, contouring the hypothesis that physicians refuse to 
submit a testimony against other physicians in the name of good fellowship. For the medical sociology, the ideas of the author contribute to the continuation of debates about the regulation activities of medicine as occupation and offers a perspective on the principles which governs the public engagement and that of the patients. (MacBrideStewart, 2014).

\section{Orientation towards physician and towards particularities of the clinical practice - Results of the "malpractice crisis"}

It is contoured the identification of a new social problem which becomes more and more real: physicians have problems of professional conduct and pathological ones. The question was if this problem has significant dimensions to justify the worry, action and financing. This thing proved to be difficult because the deficiency of environment tends to be secret. Many "moral guardians", mostly from the publicist area emphasized the identification in the public area of a multitude of social problems (abuse on the child, drug addiction, pregnancy at teenagers) and tries to prove that the problem, in the case of affected physicians, is quickly growing, it has to be sounded the alarm on a common problem which until then remained hidden from the public sight. The organizational response did not delay; programs was contoured for the "affected physicians". The initial conception that the physician is "affected" lead to a proliferation of public medical societies activity, has allowed the professional medical societies to establish the problem as one of internal responsibility of physician and have treated it as one similar to a disease than a social deviant one. The programs have tried to intervene to help the physician, more than to allow that some behaviours of the physicians become a disciplinary and license problem. The general organizational model for professional medical societies was to establish a committee for physicians with deficiencies, also composed of physicians. Confidentiality measures will be introduced to protect the physician's identity and the license to practice and, eventually, it is introduced a final sanction (for example, reference to the public license council) in case which exceed a certain severity.

The movement of this type, which regarded the physician as "affected" party was capable to occupy a significant area of professional deviation of physician, but also to maintain this thing far from the control of bodies which grant licenses. The medical occupation kept a high level of autonomy in the matter of self-regulation. The problem was not settled to a control exercised by the professional societies and there was also a reticence of certain public medical councils to allow the medical societies a full freedom to act: there are variable conditions concerning the societies' obligations to report the physicians with problems to the public councils. Also, the conditions for the occurrence of some satisfying requirements for a better control of consumers on the physician's performances have been met even though, at the same time, it excludes efficiently the patients from these control activities.

Another perspective is focused on the analysis of details of some litigations; which the parties hope to obtain, the way in which they express their needs and justify the 
behaviour. Even when a complaint is taken seriously, generally, there is a piece of discontent and the plaintiffs feel vulnerable against the dominant role of the physician; it dominates the complaints in which it is declared that there are modified forms of patient - physician interaction. The researches of Mulcahy proved that the complaints also had a long - term effect on physicians who perceived that they were not defended by the profile organizations. In the discussions with colleagues (as professional socialization process), the physicians consider that the complaints are "normal", tent to regard them as a "normal" reaction to disease and, consequently, do not reflect really the situation and personal professional actions. The complaints are symbols of higher threaten of consumption and identification of some laic assertions which prove the difficulties of integration of medical occupation within social framework and incapacity to integrate the bureaucratic models of supplying medical services (Meerabeau, 2006).

The article of López does not bring information concerning the theoretical framework of the malpractice concept but identifies different reactions of physicians against those of the nurses, just as consequence of the felt litigious risk. It is discussed about an ethnographic study of Chambliss and it is argued concerning the advantages which such studies have when observing the medical practice. Such a study is centred on the observation and analysis of daily life flows within institutional context, it is capable to explore the power relationships, institutional routines and cultural scenarios (Lopez, 2004). Depending on the perspective of each professional group involved in the care of a patient, the therapeutic attitude as well as the emotions can be different; there are situations described as crises between physicians and nurses. For example, when we take into consideration the treatment of patients with terminal diseases, the physicians tend to prescribe some "aggressive" treatments, due to various reasons, but, most probably, due to the fear of malpractice costs (Chambliss, 1996). The faith in his medical efficiency is ignored, it is forgotten the main responsibility of saving lives or, it even seems that there is a relative ignorance towards the patient's suffering. This is opposed to the nurse's frustration (to whom it is imposed to work, administer the treatments prescribed by patients) who see that the patient makes no progresses and who even asks to be let alone.

The paper of Horobin and McIntosh does not bring information concerning the theoretical framework of malpractice concept; it is based on interviews on a sample of 50 physicians and their perceptions about the available time as resource and the duty which they to fulfil concerning their attempts to create satisfying work roles are explored. It is described a contrast between the physicians from the urban and rural environment at this moment. For the physicians from urban communities, the economy of time functioned as a rare resource and which generated a risk element by establishing quickly a routine diagnostic. For the professionals from the rural environment, time was not seen as a reduced resource, but they confronted with the risk of working without additional services to support the diagnostic. As consequence, most of the physicians confronted with the problem of activities which contained a variable mix of risky situations or some routine ones. At this moment of medical practice, the aspects followed in this paper continue to be present; the litigious risk degree for the primary medical practice and for the one of the rural environments is a more reduced one. 
There is a perception in which the use of diagnostic packs or stereotypes are understood in the usual practice; the aspect is based on the grounds of the traditional clinical medicine in which the "disease" is conceptualized as an independent entity of individual person. So, while individual variations concerning the signs of disease, the reactions to diseases and the consequences of diseases must be expected, the disease itself is recognized and treated in a similar way. A finite range of diseases have a finite series of signs and symptoms which are learnt during the medical training. This method of regarding things, reported to the content of duties in the medical practice, helps us understand why the problems of "social", "psychological", "emotional" or "personality" type are often considered overwhelming for this type of practice. The solutions to various problems by the use of some routines can involve a failure risk, in unusual, severe risks, but the risks are limited for the primary medicine in the rural environment and the costs related to malpractice are reduced (Horobin \& McIntosh, 1983).

Gross does not bring information concerning the theoretical framework of the malpractice concept but position this matter in a list of factors which generate stress for a certain part of physicians (cardiologists) and in a comparative analysis of two health systems (the American and British one). The malpractice is situated on the fourth position after burnout, the diminution of autonomy and the loading with responsibility; in the inferior part of the "classification" the following have been registered: lack of resources, insufficient time, role conflicts and interpersonal conflicts from the place of work. The occupational stress which the cardiologists experiment differs depending on the health system in which they perform the activity; the rationalization of medical care differs in the United States in comparison with Great Britain. From the interviews of this exploratory study we find that the American physicians complain about the increased limitation of autonomy which results from the intrusion of government and insurance companies. The 21 British cardiologists give a higher importance to the work volume and lack of resources in the National Health Service. The stress is associated with higher types of rationalization of health in the two countries. In the United States, where is an explicit rationalization, external controls are placed during the hospitalizations, paraclinical tests and medical procedures, the physicians' fees and the use of drugs enter in a normative control process. In Great Britain, the implicit reasoning is imposed by the general limitation of financing the medical care, letting the physicians free to perform clinical studies and take decisions. However, the medical care for all the members of the society is limited by limited financing and lack of facilities, achieving the creation of some long - term queue. (Gross, 1994).

The recent initiatives of the health policies of the United Kingdom promote a "no blame culture" and the learning from side events to increase the patients' safety within the public health system NHS. Similar initiatives exist in USA and Australia. The change of "blame culture" of NHS was supported in politics by investigation documents and reports for over two decades. Some of the key concepts are used in the political discourse - "blame" (errors, mistakes) and - "culture". These are examined and reconsidered in the light of scientific social literature and some of the hypothesis referring to these terms are doubted and suggest some questions and alternative perspectives (Ehrich, 2006). 
It is recognized the intra- and inter-professional difficulty to report errors and violations from the doctors; an interpretation of social perspectives as an alternative to the approaches oriented towards the managerial matters of the patients' safety can focus on deeper structural matters of organizational matters, on the capacity of system or of the medical personnel to report mistakes and violations as a matter of patients' safety (Ehrich, 2006).

How do the physicians build the medical "interactions"? Berg states ${ }^{1}$ that the perspectives developed in the sociology of science (especially the so-called laboratory studies) can be helpful in the approach of this relatively unexplored problem. At the level of clinical action, the medical sociologists separated until now, generally, the "content" of medical action from the "social" matters, the first one representing a field which is not accessible to the sociological investigation, being pure professional matter, technical from the medical practice. This asymmetrical approach of "cognitive" and "social" elements is since the historical and examination data of patients are considered "facts" which the physician must "disclose" because there are also scientific data, considered "fixed". A "laboratory study" of solving medical problems in the clinical practice shows that these hypotheses are not valid. It is argued that the physician, when transforming the problem of a patient in a resolved problem, do not combine only some "cognitive" elements together, but he also articulates actively a series of heterogeneous elements, which are in a continuous transformation. In this construction process, the elements participate and transform in a process which can be called "routine" (Berg, 2008).

The routines ease the medial action by the materialization of some professional action methods and to avoid the transformation processes and, at the same time, provides a framework which delimits the adequate actions from those which are not considered compliant. The routines do not simply dictate the use of an instrument but define the contact between the physician and laboratory (regarded as an extended instrument) and establishes what tests are relevant to establish a diagnostic.

The list of elements which compose the routines has only a heuristic basis. Multiple "contextual" elements can be added permanently, like: the need to "cover" itself taking into consideration the possibility of materializing a "malpractice complaint", the will to act or not of the patient, regulations, the physician's involvement in the scientific, research and educational field, and so on (Konner, 1988).

The sociological perspective emphasized various involvements of malpractice; it was described as a crisis of patient's care at the level of the micro-relationship physician patient. First, there is a transfer cost under the form of higher costs or services and for third party insurances. Second of all, the economic cost for physicians can lead to a diminution of services volume (Epps, 1986). This thing was remarkable in the so-called specialties with high risk, like obstetrics where the physicians were forced to give up at practicing the occupation. In a report of 1986, the American College of Obstetrics and Gynaecology (ACOG) acknowledges that $12 \%$ of the physicians with this specialty gave

${ }^{1}$ In the paper The construction of medical disposals Medical sociology and medical problem solving in clinical practice 
up to obstetrics due to the threatening with malpractice. Moreover, many physicians from primary, family medicine reduced, during that period, the obstetrics services due to the same reasons (Annandale, 2008).

A more discussed aspect of the malpractice crisis has been the practice of "defensive medicine" about which, many researchers tell that it promotes not only useless costs or the consumer, but also lesser possibilities of choosing for the patient. It is difficult to decide to what extent the decisions taken by physicians in treating the patients are influenced by the threaten of malpractice. Hershey draws the attention on the problems associated with the "difficulty of differentiating which seems to be a good medical practice from the defensive practice of medical interventions and the need to assess subconscious aspects as the conscious influences caused by the awareness of liability". His study, based on unstructured interviews with 17 physicians from the private practice, suggest that the practice of a defensive medicine varies depending on certain "personal features of physicians and patients which they consult" (Hershey, 1982).

The response of the physician to the crisis of malpractice followed certain directions in the attempt of medicine of repairing the economic and social damages of the occupation suffered as consequence of the occurrence of this contemporary phenomenon: (1) lobby for modifications of legislation, (2) lobby for the modification of public opinion and (3) primary and secondary prevention by the "management" of physician - patient interaction (Annandale, 2008). An example was AMA Special Task Force on Liability Action which represented an educational campaign to "improve the public understanding" and to educate patients concerning the medical malpractice (Montgomery, 1987). The campaign involved the publishing of some leaflets for the patients, available in many medical practices. The public reaction was not only positive one, but sometimes it took comic aspects as it existed in a pamphlet distributed by Rhode Island. It said that the medical society told the patients that "medicine was a precise science; each patient is different and will react somehow different concerning the drugs and treatment. Despite the best efforts of a physician, some patients do not obtain the results which their physicians expect, after a certain treatment of medical procedure".

The third way in which the medical profession attempts to repair or prevent the damages caused by malpractice is represented by the modelling of interaction with the patient, being able to be constituted as source of litigation. The controversy doctrine of the informed consent is crucial to understand why physicians localize the source of costs of malpractice in the relationship physician - patient. In the complaint of negligence, the plaintiff must prove a causality between the failure of receiving the information considered necessary and the caused damages (Koopersmith, 1984). The roots of the informed consent is found in the recognition of the right to selfdetermination of the patient which could be interpreted by the fact that the "physician must give the patient enough information about the proposed treatment, such that it offers the occasion to make an "informed" or "rational" choice concerning the possibility of subjecting to a treatment" (Robertson, 1981). The capacity of informed consent to increase the self-determination of the patient can be questioned. The rhetoric concerning the informed consent offers a higher possibility for the medical paternalism. In practice, the informed consent can be more than a formality. But, 
however, its central functions in practice, are to establish a physician - patient relationship to prevent some malpractice situations. Harrison and collaborators (1985) observe, for example, that "this relationship is one from which all the obligations which fall on the physician result and without this relationship no negligence can exist or the violation of duties" (Harisson, Worth, \& Carlucci, 1985). It has been explained why physicians and lawyers cannot focus on the negligence itself, but, rather, on the failure to communicate with the patients.

\section{Conclusions}

The approaches of the medical malpractice phenomenon remain some limited to a perspective centred on a determinant as it is the communication physician - patient, therapeutic relationships, quality of medical document or costs related to the medical care. The identification of a unitary sociological theory remains a desideratum. Such a theory could offer a clearer image against the one which we can project with the current approaches.

Current research seems to be directed, separately, either to some individual determinants (such as the doctor-patient relationship or communication with the patient) or to some general or even systemic ones (such as general aspects of medical practice, related issues costs of medical care, monitoring the quality and safety of medical treatments through formal regulations or the impact of press releases). The sociological approach can bring an overall, integrative vision. Ethical aspects can also be an important element being confronted with a somewhat antagonistic analysis: ethics centred on the individual and his rights (a Hippocratic, classical ethics) and ethics centred on groups of people or populations (a functionalist ethics).

The so-called "crisis of malpractice" from the American health system had as enter the incapacity of the insurance system of supporting the avalanche of requested indemnities. The economic approach proved to be a limited one and could not explain the subsequent evolution of the phenomenon. Subsequent researches went deeply identifying a series of determinants in which the cultural factors or one which are related to the individual opinions of people proved to be important too, but the enunciation of such a unitary sociological theory delayed occurring.

\section{References}

Alaszewski, A. (2002). The impact of the Bristol Royal Infirmary disaster and inquiry on public services in Journal of Interprofessional Care, 16(4), 371-378. https://doi.org/10.1080/ 1356182021000008319

Allen LW, Creer E, L. M. (2000). Developing a patient complaint tracking system to improve performance. Joint Commission Journal on Quality and Patient Safety, 26(4), 217-226.

Annandale, E. C. (2008). The malpractice crisis and the doctor-patient relationship. Sociology of Health \& Illness, 11(1), 1-23. https://doi.org/10.1111/j.1467-9566.1989.tb00040.x

Barber, B. (1963). Some Problems in the Sociology of the Professions. Daedalus, 92(4), 669-688.

Barbot, J., \& Fillion, E. (2006). La «médecine défensive »: critique d'un concept à succès. Sciences Sociales et Santé, 24(2), 5-33. 
Berg, M. (2008). The construction of medical disposals Medical sociology and medical problem solving in clinical practice. Sociology of Health \& Illness, 14(2), 151-180. https://doi.org/10.1111/j.14679566.1992.tb00119.x

Bosk, C. L. (2003). Forgive and Remember: Managing Medical Failure. Chicago: The University of Chicago Press.

Brown, P. R. (2008). Trusting in the New NHS: instrumental versus communicative action. Sociology of Health \& Illness, 30(3), 349-363. https://doi.org/10.1111/j.1467-9566.2007.01065.x

Burstin HR, Johnson WG, Lipsitz SR, B. T. (1993). Do the poor sue more? A case-control study of malpractice claims and socio-economic status. Journal of the American Medicine Association, 270(14), 1697-1701.

Chamba, R. (2006). Key Concepts in Medical Sociology. Sociology of Health and Illness, 28(3), 376-377. https://doi.org/10.1111/j.1467-9566.2006.00497a.x

Chambliss, D. F. (1996). Beyond Caring: Hospital, Nurses and the Social Organisation of Ethics. Chicago: Chicago University Press.

Charmaz, K. (1986). Review Essay Social Science in Health Studies: An Interdisciplinary Approach. Sociology of Health and Illness, 8(3), 278-290. https://doi.org/10.1111/1467-9566.ep11340378

Charmaz, K. (1995). The Body Identity and Self: Adapting to Impairment. The Sociological Quarterly, 36(4), 657-680. https://doi.org/10.1111/j.1533-8525.1995.tb00459.x

Codman, E. A. (1917). A Study in Hospital Efficiency: as Demonstrated by the Case Report of the First Five Years of a Private Hospital. Oak Brook, IL.

Committee Report AMA "Professional liability and the physician." (1963). Journal of the American Medical Association (Vol. 183).

Danzon, P. M., Pauly, M. V., \& Kington, R. S. (1990). The effects of malpractice litigation on physicians' fees and incomes. The American Economic Review, 80(2), 122-127.

Davies, H. T. O., \& Rundall, T. G. (2000). Managing Patient Trust in Managed Care. The Milbank. Quarterly, 78(4), 609-624.

Derbyshire, R. C. (1974). Medical ethics and discipline. Journal of American Medical Association, (228), 5962.

Ehrich, K. (2006). Telling cultures: "cultural" issues for staff reporting concerns about colleagues in the UK National Health Service. Sociology of Health and Illness, 28(7), 903-926. https://doi.org/10.1111/j.1467-9566.2006.00512.x

Entwistle, T., \& Matthews, E. (2015). For society, state and self: juggling the logics of professionalism in general practice appraisal. Sociology of Health \& Illness, 37(8), 1142-1156. https://doi.org/10.1111/1467-9566.12287

Epps, C. (1986). Medical liability, 1986. Problem, prescription, prognosis. The Journal of Bone and Joint Sungery, 68(7), 1116-1124.

Fenn, P. (1987). Medical Malpractice: Theory, Evidence and Public Policy (Book). Sociology of Health and Illness, 9(3), 347-348. https://doi.org/10.1111/1467-9566.ep10958278

Fotaki, M. (2014). Can consumer choice replace trust in the National Health Service in England? Towards developing an affective psychosocial conception of trust in health care. Sociology of Health \& Illness, 36(8), 1276-1294. https://doi.org/10.1111/1467-9566.12170

Foucault, M. (1973). The birth of the clinic An Archaeology of Medical Perception. London: Tavistock Publications Limited.

Freedman, D. (2002). Clinical governance - bridging management and clinical approaches to quality in the UK. Clinica Chimica Acta, 319(2), 133-141.

Freidson, E. (2001). Professionalism, the Third Logic on the Practice of Knowledge. Chicago: University of Chicago Press. 
Gilson, L. (2003). Trust and the development of health care as a social institution. Social Science \& Medicine, 56(7), 1453-1468. https://doi.org/10.1016/S0277-9536(02)00142-9

Gorman, E. H., \& Sandefur, R. L. (2011). Golden Age, quiescence and revival: how the sociology of the professions became the study of knowledgebased work. Work and Occupations, 38(3), 275302.

Gross, E. B. (1994). Health care rationing: its effects on cardiologists in the United States and Britain. Sociology of Health and Illness, 16(1), 19-37. https:/ /doi.org/10.1111/1467-9566.ep11346997

Ham, C. (1980). The Medical Establishment and Social Responsibility/Democratic Processes for Modern Health Agencies. Sociology of Health and Illness, 2(3), 346-347. https://doi.org/10.1111/1467-9566.ep11340793

Harisson, L., Worth, M., \& Carlucci, M. A. (1985). The development of the principles of medical malpractice in the United States. Perspectives in Biology and Medicine, (29), 41-72.

Hershey, N. (1982). The defensive practice of medicine. In J. McKinlay (Ed.), Law and Ethics in Health Care. Cambridge: MIT Press.

Horobin, G., \& McIntosh, J. (1983). Time, risk and routine in general practice. Sociology of Health and Illness, 5(3), 312-331. https://doi.org/10.1111/1467-9566.ep10491839

Jensen, C. B. (2008). Sociology, systems and (patient) safety: knowledge translations in healthcare policy. Sociology of Health \& Illness, 30(2), 309-324. https://doi.org/10.1111/j.14679566.2007.01035.x

Kelly, M., Morgan, A., Ellis, S., Younger, T., Huntley, J., \& Swann, C. (2010). Evidence based public health: A review of the experience of the National Institute of Health and Clinical Excellence (NICE) of developing Public Health Guidance in England. Social Science and Medicine, (71), 1056-1062.

Kohn LT, Corrigan JM, D. M. (2000). To Err is Human: Building a Safer Health System. Washington (DC): National Academy Press. https://doi.org/10.17226/9728

Konner, M. (1988). Becoming a Doctor: A Journey of Initiation in Medical School. New York: Penguin Books.

Koopersmith, E. R. G. (1984). Informed consent: the problem of causation. Medicine and Law, (3), 231236.

Law, S., \& Polan, S. (1978). Pain and Profit: the Politics of Malpractice (1st ed.). New York: Harper \& Row.

Le Fanu, J. (2011). The Rise and Fall of Modern Medicine. London: Little Brown Book Group.

Lopez, J. (2004). How sociology can save bioethics ... maybe. Sociology of Health and Illness, 26(7), 875896. https://doi.org/10.1111/j.0141-9889.2004.00421.x

Lupton, D. (2008). Doctors on the medical profession. Sociology of Health \& Illness, 19(4), 480-497. https://doi.org/10.1111/j.1467-9566.1997.tb00414.x

MacBride-Stewart, S. (2014). Book reviews - Horowitz, R. In the Public Interest: Medical Licensing and the Disciplinary Process. New Brunswick: Rutgers University Press. 268p Sociology of Health \& Illness, 36(8), 1296-1297. https://doi.org/10.1111/1467-9566.12205

Maseide, P. (1991). Possibly abusive, often benign, and always necessary. On power and domination in medical practice. Sociology of Health and Illness, 13(4), 545-561. https://doi.org/10.1111/14679566.ep10843655

Mechanic, D. (1976). Some Social Aspects of the Medical Malpractice Dilemma. Duke Law Journal, 1975(6), 1179-1196.

Meerabeau, L. (2006). Disputing Doctors: the Socio-legal Dynamics of Complaints about Medical Care. Sociology of Health \& Illness, 28(1), 129-130. https://doi.org/10.1111/j.14679566.2006.0490e.x

Merton, R. (2007). On sociological theories of the middle range. In J. M. C. Calhoun, J. Gerteis \& \& I. V. S. Pfaff (Eds.), Classical sociological theory (p. 531-542). Malden: Blackwell Publishing. 
Montgomery, C. (1987). MDs: Treat yourpatients and their naivete. Michigan Medicine, (86), 447-448.

Morris, T. (2015). Cut it Out: The C-Section Epidemic in America. New York: New York University Press.

Morrow, C. K. (1982). Sick Doctors: The Social Construction of Professional Deviance. Social Problems, 30(1), 92-108. https://doi.org/10.2307/800187

Mount, E. (1990). Professional Ethics in Context: Institutions, Images, and Empatby and Covenant, Community, and the Common Good (1st edition). Louisville: Westminster John Knox Press.

Mulcahy, L. (2003). Disputing doctors: the socio-legal dynamics of complaints about medical care. Berkshire, UK: Open University Press.

Murray, D. (1984). In Learning to avoid claims. Jus Medicum, 6th World Congress in Medical Law. Rijksuniversiteit Gent: Centrum voor Medisch Recht.

Murray, S. F., \& Elston, M. A. (2005). The promotion of private health insurance and its implications for the social organisation of healthcare: a case study of private sector obstetric practice in Chile. Sociology of Health \&illness, 27(6), 701-721. https://doi.org/10.1111/j.14679566.2005.00470.x

Neller, A. (2015). Book reviews - Morris, T. Cut it Out: The C-section Epidemic in America. New York: New York University Press. Sociology of Health \& Illness, 37(6), 967-968. https://doi.org/10.1111/1467-9566.12274

Norris, P. (2001). How "we" are different from "them": occupational boundary maintenance in the treatment of musculo-skeletal problems. Sociology of Health \&illness, 23(1), $24-43$. https://doi.org/10.1111/1467-9566.00239

Pellegrino, E. D. (1989). Character, Virtue and Self-Interest in the Ethics of the Professions. Journal of Contemporary Health Law \& Policy, 5(1), 53-73.

Pontell, H. N., Jesilow, P. D., \& Geis, G. (1982). Policing physicians: practitioner fraud and abuse in a government medical program. Social Problems, 30(1), 117-125.

Quick, O. (2006). Outing Medical Errors: Questions of Trust and Responsibility. Medical Law Review, 14(1), 22-43. https://doi.org/10.1093/medlaw/fwi042

Rayner, G. (1981). Medical errors and the 'sick role': a speculative enquiry. Sociology of Health \& Illness, 3(3), 296-316. https://doi.org/10.1111/1467-9566.ep10486857

Robertson, G. (1981). Informed consent to medical treatment. Law Quarterly Review, (97), 102-106.

Robinson, G. O. (1986). The Medical Malpractice Crisis of the 1970's: A Retrospective. Law and Contemporary Problems, 49(2), 5-35. https://doi.org/10.2307/1191413

Roger, L., \& Joanne, N. (1985). Wrongful birth, wrongful life: the doctor between a rock and a hard place. Obstetrics and Gynecology, 66(5), 719-722.

Rogers, E. (1968). Public Health asks of sociology...Can the health sciences resolve society's problems in the absence of a science of human values and goals? Science (159), 506-508.

Rosenthal, M. M. (1995). The Incompetent Doctor - Behind Closed Doors. Buckingham: Open University Press.

Schepers, R. (1985). The legal and institutional development of the Belgian medical profession in the nineteenth century. Sociology of Health \& Illness, 7(3), 314-341. https://doi.org/10.1111/14679566.ep10832342

Seale, C. (2008). Mapping the field of medical sociology: a comparative analysis of journals. Sociology of Health \& Illness, 30(5), 677-695. https://doi.org/10.1111/j.1467-9566.2008.01090.x

Sofronie, M. (2017). Despăgubire uriaşă într-un caz de malpraxis: un spital din România trebuie să plătească o jumătate de milion de euro. Adevarul. Retrieved from http://adevarul.ro/ locale/slobozia/despagubire-uriasa-intr-un-caz-malpraxis-spital-romania-trebuie-plateascajumatate-milion-euro-1_58b6a79f5ab6550cb8ed8615/index.html 
Somers, H. M. (1977). The Malpractice Controversy and the Quality of Patient Care. The Milbank Quarterly, 55(2), 193-232.

Stacey, M. (1988). Dealing with Medical Malpractice, the British and Swedish Experience (Book). Sociology of Health and Illness, 10(4), 614-615. https://doi.org/10.1111/1467-9566.ep10838013

Starr, P. (1982). The Social Transformation of American Medicine: The Rise of A Sovereign Profession And The Making of $A$ V ast Industry. New York: Basic Books.

Stimson, G. V. (1985). Recent developments in professional control: the impaired physician movement in the USA. Sociology of Health EIIlness, 7(2), 141-166. https://doi.org/10.1111/14679566.ep10949053

Straus, R. (1957). The Nature and Status of Medical Sociology. American Sociological Review, 22(2), 200204.

Tannen, D., \& Wallat, C. (1987). Interactive Frames and Knowledge Schemas in Interaction: Examples from a Medical Examination/Interview. Social Psychology Quarterly, 50(2), 205-216.

Taylor, K. M. (1988). 'Telling bad news': physicians and the disclosure of undesirable information. Sociology of Health of Illness, 10(2), 109-132. https://doi.org/10.1111/j.14679566.1988.tb00001.x

Titmuss, R. M. (1973). The Gift Relationship: From Human Blood to Social Policy. Harmondsworth: Penguin Books.

Tomes, N. (1985). The social transformation of American medicine: an historical perspective. Sociology of Health and Illness, 7(2), 248-259. https://doi.org/10.1111/1467-9566.ep10949093

Turner, B. (1995). Medical Power and Social Knowledge (2nd ed.). London: Sage Publications UK.

Wallen, J., Waitzkin, H., \& Stoeckle, J. (1979). Physician Stereotypes about Female Health and Illness: A Study of Patient's Sex and the Informative Process during Medical Interviews. Women \& Health, 4(2), 135-147.

Waring, J. (2007). Adaptive regulation or governmentality: patient safety and the changing regulation of medicine. Sociology of Health \& Illness, 29(2), 163-179. https://doi.org/10.1111/j.14679566.2007.00527.x

Waring, J., Allen, D., Braithwaite, J., \& Sandall, J. (2016). Healthcare quality and safety: a review of policy, practice and research. Sociology of Health \& Illness, 38(2), 198-215. https://doi.org/ 10.1111/1467-9566.12391

Wilensky, H. L. (1964). The Professionalization of Everyone? American Journal of Sociology, 70(2), 137158.

Winance, M., Barbot, J., \& Parizot, I. (2017). From loss to repair. A study of body narratives in patient claims for medical injury. Sociology of Health \&o Illness. https://doi.org/10.1111/14679566.12620

Young, J. T. (2004). Illness behaviour: a selective review and synthesis. Sociology of Health and Illness, 26(1), 1-31. https://doi.org/10.1111/j.1467-9566.2004.00376.x 